\title{
DIMETHYL 9-OCTADECENEDIOATE AND 9-OKTADECENE FROM METHYL OLEATE VIA A RUTHENIUM-CATALYZED HOMO OLEFIN METATHESIS REACTION
}

\author{
Robby Roswanda ${ }^{1}$, Ilham Ardatul Putra ${ }^{1}$, Didin Mujahidin ${ }^{1 *}$ \\ ${ }^{1}$ Division of Organic Chemistry, Faculty of Mathematics and Natural Sciences, Institut Teknologi \\ Bandung, Jl. Ganesha No. 10 Bandung 40132, Indonesia
}

(Received: February 2017 / Revised: June 2017 / Accepted: October 2017)

\begin{abstract}
Oleic acid, one of the major components of palm oil, has attracted much interest in modern oleochemistry. The internal olefin group in oleic acid is a useful functional group in the transformation of a fatty acid to other functional chemicals and materials. In this paper, we discuss the application of the olefin metathesis reaction by preparing a long-chain dicarboxylic acid and alkene from the ester of oleic acid. The internal olefin metathesis reaction of methyl oleate produced dimethyl 9-oktadecendioate and 9-octadecene in the presence of a ruthenium Grubbs II (second generation) catalyst with a 51\% yield. We also found that there was a higher amount of the $\mathrm{E}$ isomer products than the $\mathrm{Z}$ isomer products.
\end{abstract}

Keywords: Dimethyl 9-oktadecenedioate; Methyl oleate; Olefin metathesis; 9-oktadecene

\section{INTRODUCTION}

Nowadays, attention on exploring renewable resources as feeds for the chemical industry is increasing rapidly in compliance with the issue of the decreasing availability of raw materials from fossil fuels (Mol, 1998). The values, availability, and environmental impacts of their products are the reasons for the chemical industry wishing to avoid raw materials from fossils. For that reason, the switch to renewable source for raw materials is inevitable because of the low price and the availability from natural seed oil (Winkler \& Meier, 2014).

Indonesia is the biggest palm-oil producer in the world. Mostly, palm oil is used as cooking oil and biodiesel. One report states that palm oil can be decarboxylated to yield liquid hydrocarbons (Susanto et al., 2016). However, the derivatives of this commodity, which are highly value-added materials, are still very limited. In order to overcome that problem, the derivatives of palm oil are very important for increasing the value of Indonesia's palm-oil exports. With the increasing awareness from the government of the importance of palm oil and the growing capabilities of Indonesian chemists, the derivatization of palm oil has been a popular subject in Indonesian research community.

\footnotetext{
*Corresponding author's email: didin@chem.itb.ac.id, Tel: +6222 2502103, Fax: +6222 2504154
}

Permalink/DOI: https://doi.org/10.14716/ijtech.v8i8.772 
Oleic acid is one of the major components in palm oil comprising around 36-44\%. This fatty acid, monounsaturated at C-9, is an exemplary starting material for producing several fine chemicals and materials using various methods, such as olefin metathesis, ozonolysis, and epoxidation (Desnelli et al., 2015). The ethenolysis of oleic acid will produce 1-decene and 9decenoate. These compounds have important roles in drug production, food additives, lubricant formulations, herbicides, perfumes, pheromones, coatings, and smart materials (Biermann et al., 2011). In addition, the synthesis of 1-decene from renewable natural oils could perhaps replace the established process for producing medium long hydrocarbons from fossils in the petrochemical industry (Pillai et al., 2013).

In our previous study, we applied olefin metathesis in the ethenolysis of palm oil to produce 9decenoate and 1-decene. However, the purification of these products from other components in palm oil has still not been accomplished (Desnelli et al., 2015). In this study, we conducted a more straightforward homo olefin metathesis by using methyl oleate to yield 9-octadecene and dimethyl 9-octadecendioate using a Grubbs II catalyst (Figure 1).

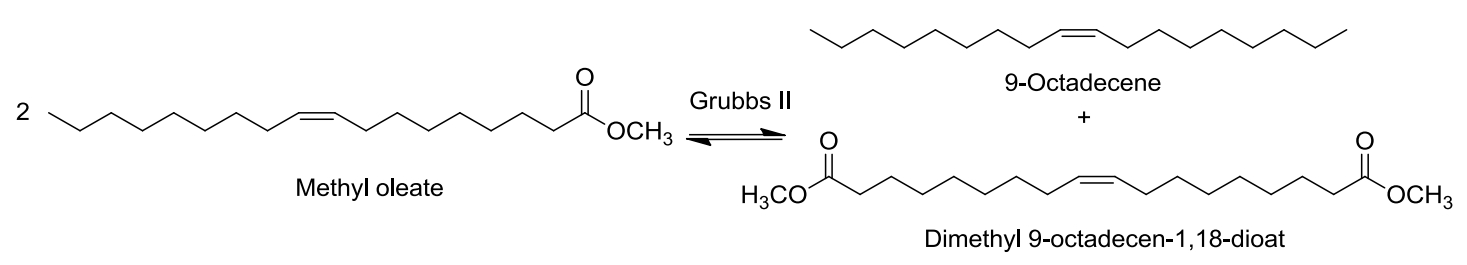

Scheme 1 Homo olefin metathesis of methyl oleate

The olefin metathesis reaction is strongly dependent on the type of catalyst. Several transition metal carbene complexes, including Fischer or Schrock carbene, can facilitate the olefin metathesis reaction. However, the most important catalysts for this reaction are the carbene complexes of tungsten, molybdenum, and ruthenium (Mol, 1998). The structures of the common catalysts of the olefin metathesis reaction are shown in Figure 1. Although molybdenum and tungsten complexes work efficiently as catalysts for the olefin metathesis reaction, ruthenium complexes have several advantages, including being air stable, easy to handle, and tolerant of there being many functional groups in the substrates. For these reasons, we used a Grubbs II catalyst for the olefin metathesis reaction on methyl oleate.
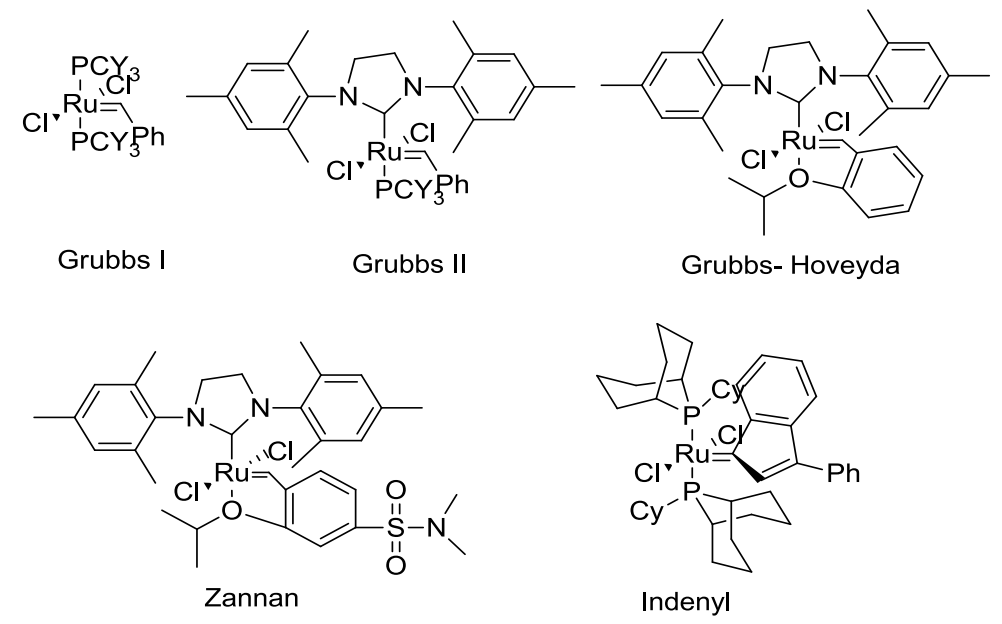

Figure 1 Catalysts for the olefin metathesis reaction 


\section{METHODOLOGY}

\subsection{Materials}

Oleic acid, methanol, sulfuric acid, distilled water, n-hexane, ethyl anhydrous acetate $\left(\mathrm{Mg}_{2} \mathrm{SO}_{4}\right)$, and silica gel were purchased from local suppliers. All reagents were used without further purification. The ruthenium-metal-based catalyst (Grubbs II) was purchased from Sigma Aldrich. ${ }^{1} \mathrm{H}$ NMR (nuclear magnetic resonance) spectra were recorded on an Agilent DD2 system, operating at $500 \mathrm{MHz}(1 \mathrm{H})$ (Agilent Technologies Inc., Santa Clara, CA, USA) or a Spinsolve operating at $43 \mathrm{MHz}$ (Magritex Ltd, Wellington, New Zealand), and using CDCl3 with tetramethylsilane (TMS) as an internal standard (chemical shift $\delta, \mathrm{ppm}$ ).

\subsection{Esterification of Oleic Acid (Kusmiyati, 2008)}

Methyl oleate was prepared by reacting $100 \mathrm{~mL}$ of oleic acid $(94.5 \mathrm{mg} ; 0.316 \mathrm{~mol})$ and $102 \mathrm{~mL}$ of methanol $(81.15 \mathrm{mg} ; 2.53 \mathrm{~mol})(1: 8 \mathrm{w} / \mathrm{w})$ in the presence of sulfuric acid, as a catalyst of $1 \%$ (w/w), under reflux conditions for 3 hours. The completion of the reaction was monitored using thin-layer chromatography (TLC) (n-hexane:ethyl acetate/9:1). The completed reaction was washed with water and dried with anhydrous $\mathrm{MgSO}_{4}$.

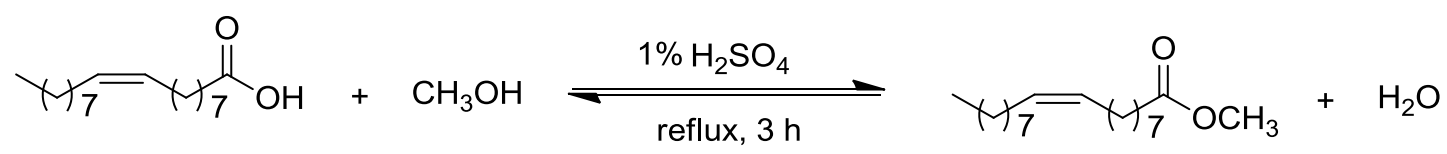

Scheme 2 Esterification reaction of oleic acid

Methyl oleate with a yield of 99\%. ${ }^{1} \mathrm{H}$ NMR $(500 \mathrm{MHz}, \mathrm{CDCl} 3): \delta_{\mathrm{H}} 5.42(\mathrm{q}, 2 \mathrm{H}), 3.65(s, 3 \mathrm{H})$, $2.32(t, 2 \mathrm{H}), 2.18(m, 4 \mathrm{H}), 1.64(m, 2 \mathrm{H}), 1.29(s, 20 \mathrm{H}), 1.31(q, 3 \mathrm{H}), 0.88(t, 3 \mathrm{H}) ;{ }^{13} \mathrm{C}$ NMR $\left(125 \mathrm{MHz}, \mathrm{CDCl}_{3}\right): \delta_{\mathrm{C}} 173.1 ; 130.6 ; 51.9 ; 33.6 ; 31.9 ; 29.9 ; 29.7 ; 29.0 ; 29.3 ; 27.7 ; 25.0 ; 22.7$; 14.1.

\subsection{Homo Olefin Metathesis Methyl Oleic Reaction}

A homo olefin metathesis was carried out in a solution of methyl oleate and Grubbs catalyst II (500:1), with toluene as the solvent, at $75^{\circ} \mathrm{C}$ for 9 hours. Silica gel was added to the completed reaction to deactivate the catalyst, and the solution was extracted with water to remove the catalyst. The organic layer was then dried with anhydrous sodium sulfate, filtered to get a yellowish viscous solution, and was finally evaporated in vacuo. The purification of the products was carried out using flash column chromatography (n-hexane:ethyl acetate/95:5) to get 9-octadecena and dimethyl 9-octadecendioate.<smiles>CCCC=CNC(=O)OC</smiles>

Methyl oleate
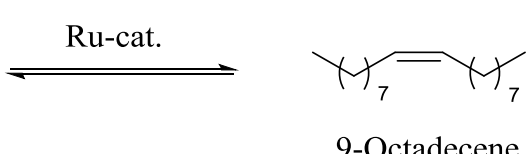

$(\mathrm{E} / \mathrm{Z}: 8 / 2)$<smiles>COC(=O)C=CC=CNC(=O)OC</smiles>

Dimethyl 9-Octadecenedioate

$(\mathrm{E} / \mathrm{Z}: 8 / 2)$

Scheme 3 Homo olefin metathesis of methyl oleate

Dimethyl 9-octadecenedioate with a yield of $25 \% .{ }^{1} \mathrm{H}$ NMR $\left(500 \mathrm{MHz}, \mathrm{CDCl}_{3}\right): \delta_{\mathrm{H}} 5.42(q$, $2 \mathrm{H}), 3.65(s, 6 \mathrm{H}), 2.32(t, 4 \mathrm{H}), 2.18(m, 4 \mathrm{H}), 1.64(m, 4 \mathrm{H}), 1.29(\mathrm{~m}, 16 \mathrm{H}) ;{ }^{13} \mathrm{C}$ NMR $(125 \mathrm{MHz}$, $\left.\mathrm{CDCl}_{3}\right): \delta_{\mathrm{C}} 173.1 ; 130.7 ; 51.9 ; 33.6 ; 29.9 ; 29.4 ; 29.1 ; 27.7 ; 25.5$.

9-Octadecene with a yield of 26\%. ${ }^{1} \mathrm{H}$ NMR $\left(500 \mathrm{MHz}, \mathrm{CDCl}_{3}\right): \delta_{\mathrm{H}} 5.42(q, 2 \mathrm{H}), 2.18(\mathrm{~m}, 4 \mathrm{H})$, $1.31(m, 4 \mathrm{H}), 1.29(s, 20 \mathrm{H}), 0.88(t, 6 \mathrm{H}) ;{ }^{13} \mathrm{C} \mathrm{NMR}\left(125 \mathrm{MHz}, \mathrm{CDCl}_{3}\right): \delta_{\mathrm{C}} 130.6 ; 31.9 ; 29.9$; $29.3 ; 27.7 ; 22.7 ; 14.1$. 


\section{RESULTS AND DISCUSSION}

\subsection{Esterification Reaction}

We prepared the reagent for the olefin metathesis of methyl oleate via the esterification of oleic acid with methanol. Methanol was used excessively to shift the equilibrium of the reaction toward the products. The yield obtained was $99 \%$ and the structure of the product was confirmed by using ${ }^{1} \mathrm{H}$ NMR. The ${ }^{1} \mathrm{H}-\mathrm{NMR}$ spectrum (Figure 2) shows a singlet peak at 3.6 ppm and that indicates the attachment of methoxy to form the ester of oleic acid. By comparing the NMR spectrum of oleic acid with that of its methyl ester, it can be seen that the ester has the same stereochemistry, which is Z (Figure 2).

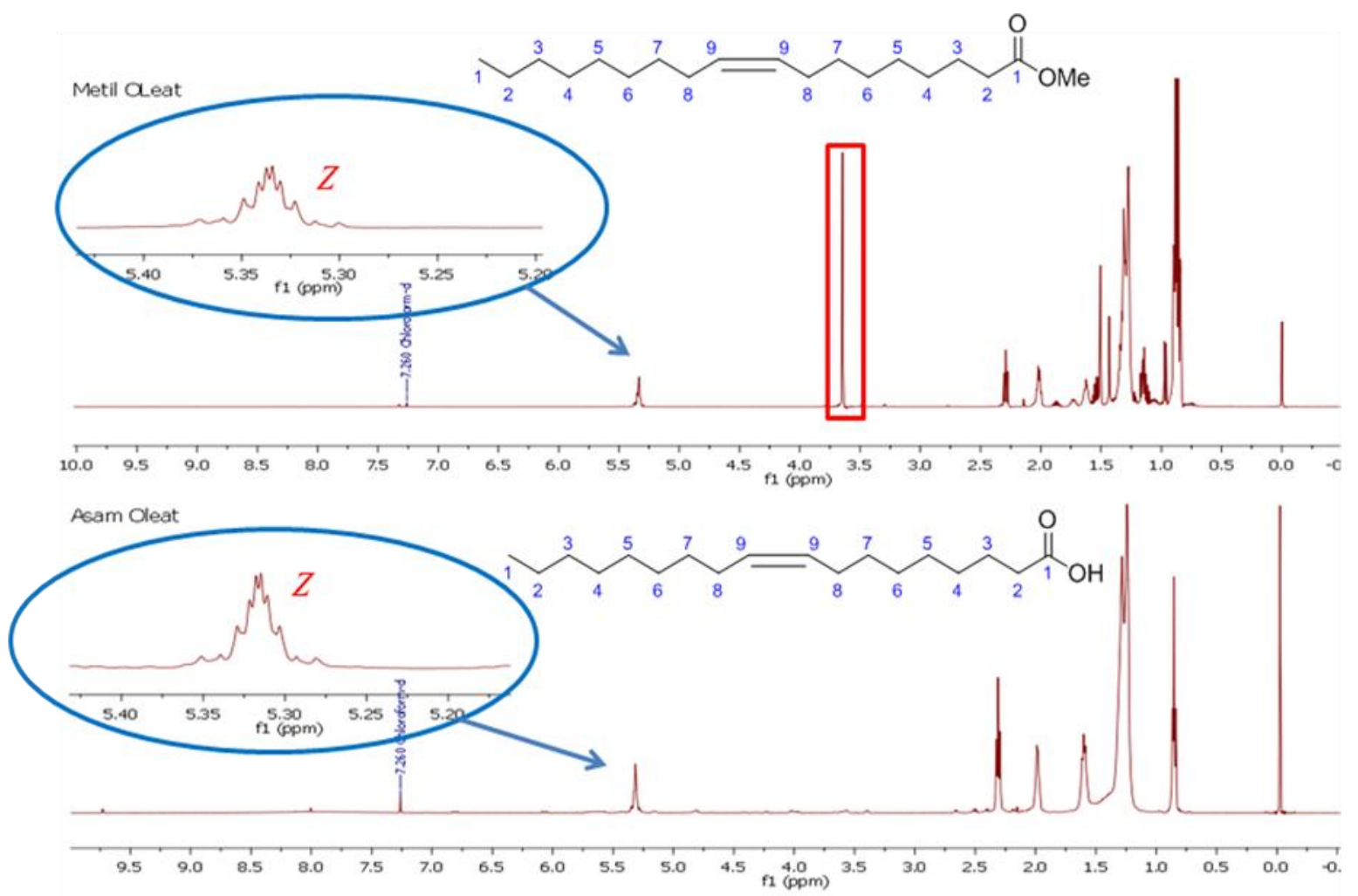

Figure $2{ }^{1} \mathrm{H}$ NMR Spectra of oleic acid and methyl oleate

\subsection{Homo Olefin Metathesis Reaction}

The homo olefin metathesis reactions were performed using a Grubbs II catalyst to produce dimethyl 9-octadecendioate and 9-octadecene. The structures of the two compounds have been confirmed by NMR, as shown in Figure 3. From the spectrum of the proton NMR, the two products still appear to be a mixture of $E$ and $Z$ isomers. This is illustrated in Figure 3. The two isomers are shown as peaks at $5.38 \mathrm{ppm}$ and $5.42 \mathrm{ppm}$. By comparing the integration, it is revealed that the two isomers have a ratio of 8:2. From the literature (Tüzün et al., 2016), it appears that the $\mathrm{E}$ isomer has a more deshielding peak than the $Z$ isomer. It can be assumed that the major product from the homo olefin metathesis is the $E$ isomer. 


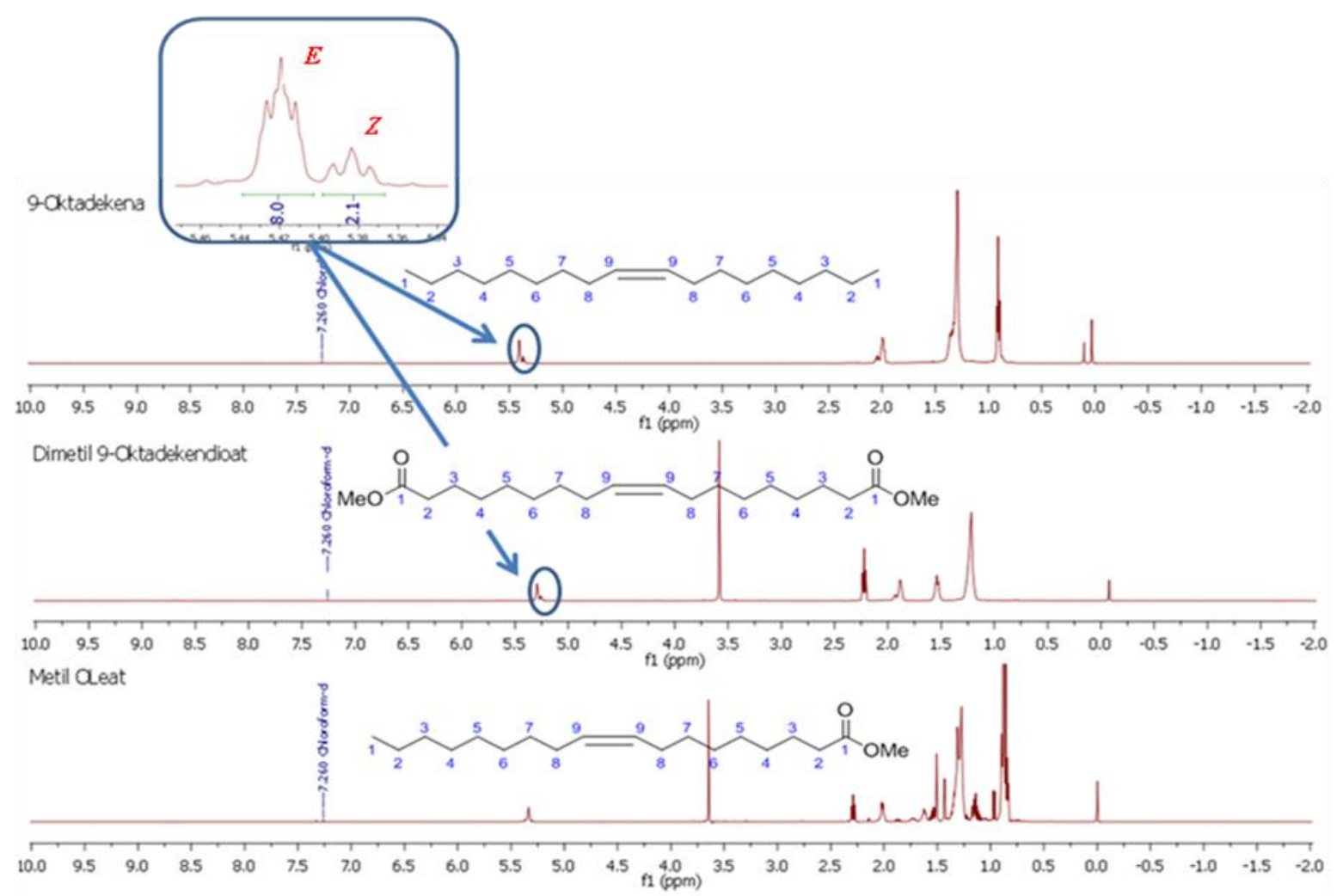

Figure $3{ }^{1} \mathrm{H}$ NMR Spectra of the products of the homo olefin metathesis reaction and methyl oleate

The effect of a solvent on the homo olefin metathesis was also explored. Table 1 summarizes the effects of the solvent. When the reaction was carried out neat (that is, without a solvent), it generated a moderate yield of $21 \%$. However, the yield was significantly increased by using only $1 \mathrm{~mL}$ of toluene as a solvent. The yield did not really change after the addition of more solvent $(10 \mathrm{~mL})$. This shows the importance of a solvent for dissolving all reagents and the catalyst. Without any solvent, the catalyst will not dissolve completely, and if there is too much solvent, the reaction mixture will be too diluted to generate products.

Table 1 Effect of solvents on homo olefin metathesis reaction

\begin{tabular}{ccc}
\hline Entry & Solvent (toluene) & \% yield \\
\hline I & Neat & 21 \\
II & $1 \mathrm{~mL}$ & 51 \\
III & $10 \mathrm{~mL}$ & 40 \\
\hline
\end{tabular}

Reaction conditions: $2 \mathrm{~mL}$ methyl oleate $(0.0059 \mathrm{~mol}, 1.749 \mathrm{mg}), 75^{\circ} \mathrm{C}$, $0.2 \%$ catalyst, $9 \mathrm{~h}$, and under an $\mathrm{N}_{2}$ atmosphere; the yields were determined after purification using flash chromatography on silica gel.

The optimization of the amount of catalyst needed was also explored. The results are detailed in Table 2. As expected, by reducing the amount of catalyst used compared to the substrate, the yield also decreased. However, the decrease was not very significant, which indicates that the homo olefin metathesis does not require much of the catalyst. The reaction can still produce an acceptable yield even after using an amount of catalyst as small as $0.1 \%$. 
Table 2 Results of optimizing the catalyst amount

\begin{tabular}{ccc}
\hline Entry & \%mol Catalyst & \% Yield \\
\hline I & 0.33 & 47 \\
II & 0.20 & 51 \\
III & 0.13 & 47 \\
IV & 0.10 & 40 \\
\hline
\end{tabular}

Reaction conditions: $2 \mathrm{~mL}$ methyl oleate $0.0059 \mathrm{~mol}, 1.749$ $\mathrm{mg}, 75^{\circ} \mathrm{C}, 9 \mathrm{~h}$, and under an $\mathrm{N}_{2}$ atmosphere; the yields were determined after purification by flash chromatography on silica gel.

\section{CONCLUSION}

The homo olefin metathesis of methyl oleate was successfully carried out using a Grubbs II catalyst. The products were 9-octadecene and dimethyl 9-octadecendioate. Both products exist as a mixture of geometrical isomers, and the ratio of $E / Z$ isomers is $8: 2$. The best yield was achieved by using only $1 \mathrm{~mL}$ of solvent and $1 \mathrm{~mL}$ of methyl oleate, which gave a $51 \%$ yield. It was also demonstrated that this homo olefin metathesis does not require much of the catalyst, since the decrease in yield that accompanies the decrease in the amount of catalyst was not very significant. This paper showed a promising start in developing the derivatization of palm-oil products in Indonesia.

\section{ACKNOWLEDGMENT}

The authors would like to thank Badan Pengelola Dana Perkebunan Kelapa Sawit (BPDPKS) for funding this research.

\section{REFERENCES}

Biermann, U., Bornscheuer, U., Meier, M.A.R., Metzger, J.O., Schäfer, H.J., 2011. Oils and Fats as Renewable Raw Materials in Chemistry. Angewandte Chemie International Edition, Volume 50(17), pp. 3854-3871

Desnelli, Mujahidin, D., Permana, Y., Radiman, C.L., 2015. The Olefin Reaction between Crude Palm Oil Fatty Acid Methyl Ester (CPO FAME) and Ethylene using Grubbs II Catalyst. Procedia Chemistry, Volume 17, pp. 44-48

Forman, G.S., Bellabarba, R.M., Tooze, R.P., Slawin, A.M.Z., Karch, R. Winde, R., 2006. Metathesis of Renewable Unsaturated Fatty Acid Esters Catalysed by a Phobanindenylidene Ruthenium Catalyst. Journal of Organometallic Chemistry, Volume 691(2425), pp. 5513-5516

Kusmiyati, 2008. The Catalytic Reaction of Esterification of Oleic Acid and Methanol into Biodiesel by Reactive Distillation Method (Reaksi Katalitis Esterifikasi Asam Oleat dan Metanol menjadi Biodiesel dengan Metode Distilasi Reaktif). Reaktor, Volume 12(2), pp. 78-82 (in Bahasa)

Mol, J.C., Buffon, R., 1998. Metathesis in Oleochemistry. Journal of Brazilian Chemistry Society, Volume 9(1), pp. 1-11

Montero de Espinosa, L., Meier, M.A.R., 2011. Plant Oils: The Perfect Renewable Resource for Polymer Science. European Polymer Journal, Volume 47(5), pp. 837-852

Morzycki, J.W., 2011. Application of Olefin Metathesis in the Synthesis of Steroids. Steroids, Volume 76(10-11), pp. 949-966 
Pillai, S.K., Abidli, A., Belkacemi, K., 2014. Triacylglycerol Self-metathesis over Highly Chemoselective Methyltrioxorhenium Supported on $\mathrm{ZnCl}_{2}$-promoted Mesoporous Alumina. Applied Catalysis A: General, Volume 479, pp. 121-133

Pillai, S.K., Hamoudi, S., Belkacemi, K., 2013. Functionalized Value-added Products via Metathesis of Methyloleate over Methyltrioxorhenium Supported on $\mathrm{ZnCl}_{2}$-promoted Mesoporous Alumina. Fuel, Volume 110, pp. 32-39

Scholl, M., Ding, S., Lee, C.W., Grubbs, R.H., 1999. Synthesis and Activity of a New Generation of Ruthenium-based Olefin Metathesis Catalysts Coordinated with 1,3dimesityl-4,5-dihydroimidazol-2-ylidene Ligands. Organic letters, Volume 1(6), pp. $953-$ 956

Susanto, B.H., Prakarsa, M.B., Nasikin, M., Sukirno. Synthesis of Renewable Diesel from Palm Oil and Jatropha Curcas Oil through Hydrodeoxygenation using NiMo/ZAL. International Journal of Technology, Volume 7(8), pp. 1405-1412

Tüzün, A., Lligadas, G., Ronda, J.C., Galià, M., Cádiz, V., 2016. Castor Oil-derived Benzoxazines: Synthesis, Self-Metathesis and Properties of the Resulting Thermosets. European Polymer Journal, Volume 75, pp. 56-66

Winkler, M., Meier, M.A.R., 2014. Olefin Cross-Metathesis as a Valuable Tool for the Preparation of Renewable Polyesters and Polyamides from Unsaturated Fatty Acid Esters and Carbamates. Green Chemistry, Volume 16, pp. 3335-3340

Yao, Q., 2000. A Soluble Polymer-bound Ruthenium Carbene Complex: A Robust and Reusable Catalyst for Ring-Closing Olefin Metathesis. Angewandte Chemie International Edition, Volume 39(21), pp. 3896-3898 